\title{
Influence of Temperature on Discharge Process of Misch Metal-Based Hydrogen Storage Alloy Electrodes
}

\author{
Chiaki IWAKURA, ${ }^{*}$ Hiroshi SENOH, Kohji MORIMOTO, Yasutaka HARA, \\ and Hiroshi INOUE
}

Department of Applied Chemistry, Graduate School of Engineering, Osaka Prefecture University (1-1 Gakuencho, Sakai, Osaka 599-8531, Japan)

Received December 6, 2000 ; Accepted September 6, 2001

\begin{abstract}
For the purpose of clarifying the reason why the discharge capacity of a misch metal (Mm)-based hydrogen storage alloy negative electrode in nickel-metal hydride battery drastically decreases at relatively low temperatures, the activation energies for hydrogen diffusion in the alloy bulk, charge-transfer reaction on the electrode surface and the electric conductivity of $\mathrm{KOH}$ solution were evaluated in the temperature range of $25^{\circ} \mathrm{C}$ to $-40^{\circ} \mathrm{C}$. By comparing the activation energies with one another, it was clarified that both the hydrogen diffusion and the charge-transfer reaction significantly influenced the discharge process at relatively low temperatures. The addition of Mo to the $\mathrm{MmNi}_{3.6} \mathrm{Mn}_{0.4} \mathrm{Al}_{0.3} \mathrm{CO}_{0.7}$ alloy was found to be effective for the improvement of the high-rate dischargeability at relatively low temperatures.
\end{abstract}

Key Words : Hydrogen Storage Alloy, Nickel-Metal Hydride Battery, Low Temperature, Dischargeability

\section{Introduction}

During the last decade, the nickel-metal hydride (Ni$\mathrm{MH}$ ) battery has attracted significant attention for developing as a new high performance battery in electric vehicles (EVs) because of high power density, high-rate dischargeability, long cycle life and environment-friendly property. ${ }^{1,2)}$ The Ni-MH battery for EVs has to satisfy a stable performance in a wide temperature range of $40^{\circ} \mathrm{C}$ to $-20^{\circ} \mathrm{C}, 3$ but the discharge capacity of the negative electrodes decrease drastically with decreasing temperature due to a rapid increase in the hydrogen overpotential. ${ }^{4,5)}$

The discharge process of the negative electrodes is known to mainly consist of the hydrogen diffusion in the alloy bulk and the charge-transfer reaction on the electrode surface. In addition, the electrolyte solution resistance may affect the discharge process at relatively low temperatures. It has been reported that the dischargeability of the negative electrodes at relatively low temperatures depended on the hydrogen diffusion ${ }^{4,6)}$ or the charge-transfer reaction. ${ }^{7)}$ For instance, according to our previous paper, ${ }^{4}$ the hydrogen overpotential of LaNistype alloy electrodes in the discharge process increased with decreasing temperature because of the dominant hydrogen diffusion. On the other hand, Markin et al. ${ }^{7}$ reported that the voltage loss of the Ni-MH battery at $40^{\circ} \mathrm{C}$ was much higher than that at room temperature because of the low electrocatalytic activity for $\mathrm{LaNi}_{5}$ alloy electrode. The kinetics of each step in the discharge process at relatively low temperatures have been studied so far, but the rate-determining step in the discharge process has never been revealed clearly by now.

In this study, various factors influencing the discharge process of a $\mathrm{MmNi}_{3.6} \mathrm{Mn}_{0.4} \mathrm{Al}_{0.3} \mathrm{Co}_{0.7}$ alloy electrode in the temperature range of $25^{\circ} \mathrm{C}$ to $-40^{\circ} \mathrm{C}$ were quantitatively investigated. In addition, the activation energies for the hydrogen diffusion in the alloy bulk, the charge-transfer reaction on the electrode surface and the electric conductivity of $\mathrm{KOH}$ solution were determined and compared with each other. Furthermore, for the improvement of the dischargeability at relatively low temperatures the addition of Mo to the $\mathrm{MmNi}_{3.6} \mathrm{Mn}_{0.4} \mathrm{Al}_{0.3} \mathrm{Co}_{0.7}$ alloy was attempted. Notten and Hokkeling ${ }^{8)}$ reported that the addition of Mo to the nonstoichiometric $\mathrm{AB}_{5}$-type alloys improved the discharge efficiency at $0^{\circ} \mathrm{C}$ from $34 \%$ to $90 \%$ due to the appearance of $\mathrm{MoCo}_{3}$ phase with high electrocatalytic activity. We expected the similar catalytic effect in this study.

\section{Experimental}

Mm-based hydrogen storage alloys with the compositions of $\mathrm{MmNi}_{3.6} \mathrm{Mn}_{0.4} \mathrm{Al}_{0.3} \mathrm{Co}_{0.7} \mathrm{Mo}_{\mathrm{x}}(0 \leq \times \leq 0.5)$ were prepared by arc melting under an $\mathrm{Ar}$ atmosphere. The preparation of the disk-type and powder-type electrodes and the setup of the electrochemical cell were similar as described in our previous paper. ${ }^{9}$ A deaerated $6 \mathrm{M}$ $\mathrm{KOH}$ solution was used as an electrolyte solution and all measurements were performed in a temperaturecontrolled bath ranging from $25^{\circ} \mathrm{C}$ to $-40^{\circ} \mathrm{C}$. The electric conductivity of $\mathrm{KOH}$ solution was determined in the same temperature range by a typical method using a Kohlrausch bridge.

For initial activation of the powder-type electrode, charge-discharge cycling was repeated 10 times at $25^{\circ} \mathrm{C}$ in the following way. The negative electrode was charged at $100 \mathrm{~mA} \mathrm{~g}^{-1}$ for $3.5 \mathrm{~h}$, followed by resting for $0.5 \mathrm{~h}$. It was then discharged at $40 \mathrm{~mA} \mathrm{~g}^{-1}$ to the cut-off potential of $-0.65 \mathrm{~V}$ vs. $\mathrm{Hg} / \mathrm{HgO}$. After the initial activation, the 
cell was adjusted to given temperature. Subsequently, linear micro-polarization measurement for the evaluation of the exchange current density was made at a scan rate of $1 \mathrm{mV} \mathrm{s}^{-1}$ in the vicinity of the equilibrium potential $( \pm 5$ $\mathrm{mV})$. AC impedance measurement was carried out in the frequency range of $10 \mathrm{kHz}$ to $10 \mathrm{mHz}$ with the perturbation of $10 \mathrm{mV}$. The impedance spectra were fitted to an equivalent circuit using a non-linear least squares (NLLS) fit program, EQIVCT, ${ }^{10}$ to evaluate the electrolyte solution resistance and charge-transfer resistance. The highrate dischargeability (HRD) was determined in the following way. After the activated negative electrode was charged at $100 \mathrm{~mA} \mathrm{~g}^{-1}$ for $3.5 \mathrm{~h}$, followed by resting for $0.5 \mathrm{~h}$, it was discharged to $-0.65 \mathrm{~V}$ vs. $\mathrm{Hg} / \mathrm{HgO}$ at any discharge current density $\left(i \mathrm{~mA} \mathrm{~g}^{-1}\right)$. The measured discharge capacity was represented as $C_{i}$. After standing the open circuit for $10 \mathrm{~min}$, the negative electrode was further discharged at $10 \mathrm{~mA} \mathrm{~g}^{-1}$, which was represented as $C_{10}$. The HRD value was defined by the following equation:

$$
\operatorname{HRD}(\%)=100 C_{i} /\left(C_{i}+C_{10}\right)
$$

Fick's diffusion coefficient of hydrogen $\left(D_{\mathrm{H}}\right)$ in the alloy bulk was evaluated at various hydrogen concentrations and temperatures by the potential step method using a disk-type electrode. ${ }^{11)}$ After absorbing hydrogen of given concentration electrochemically, an anodic potential step of $200 \mathrm{mV}$ from the equilibrium potential was applied to the disk-type electrode. In general, if the potential is positively stepped, adsorbed hydrogen on alloy surface is oxidized quickly and hydrogen in alloy bulk diffuses towards the surface at a velocity proportional to its concentration gradient with decreasing surface concentration of the adsorbed hydrogen. In the time range that hydrogen diffusion is rate-determining, the following equation is valid. ${ }^{12}$

$$
\ln i=\ln \left(2 F A c D_{\mathrm{H}} / \delta\right)-\left(\pi^{2} D_{\mathrm{H}} / 4 \delta^{2}\right) t
$$

where $F, A, c, \delta$ are Faraday constant, surface area $\left(\mathrm{cm}^{2}\right)$, hydrogen concentration $\left(\mathrm{mol} \mathrm{cm}{ }^{-3}\right)$ and thickness of diffusion layer $(\mathrm{cm})$, respectively. The time course of the logarithmic oxidation current $(i)$ was measured at various temperatures and hydrogen concentrations, and the $\ln i$ vs. $t$ plot was linear from $c a .20 \mathrm{~s}$ to $30 \mathrm{~s}$, that is, the end of the measurement, in any case. From a slope of a linear part of each plot, the $D_{\mathrm{H}}$ value was determined.

Crystallographic characterization of the alloys was carried out using an X-ray diffractometer. ${ }^{10)}$ Surface morphology and distribution of surface components for the negative electrodes were characterized by scanning electron microscopy (SEM) and electron probe microanalysis (EPMA), respectively. ${ }^{13)}$

\section{Results and Discussion}

3. 1 Quantitative evaluation of various factors influencing the dischargeability of a $\mathrm{MmNi}_{3.6} \mathrm{Mn}_{0.4} \mathrm{Al}_{0.3} \mathrm{Co}_{0.7}$ alloy electrode at relatively low temperatures

3. 1. 1 Hydrogen diffusion in the alloy bulk
Figure 1 shows the $D_{\mathrm{H}}$ values evaluated at various hydrogen concentrations $(n)$. In all cases, the $D_{\mathrm{H}}$ values decreased with an increase in the $n$ value, suggesting that the hydrogen diffusion is prevented due to the increased interaction between absorbed hydrogen atoms and the host materials. ${ }^{11}$ At each temperature, Einstein diffusion coefficient $\left(D^{*}\right)$ was evaluated from each y-intercept of the $D_{\text {H }}$ vs. $n$ plot. The $D^{*}$ value is defined as the diffusion coefficient of hydrogen when hydrogen concentration is zero, that is, there is no interaction between the absorbed hydrogen atoms and the host materials. These results are summarized in Fig. 2. The $D^{*}$ value at $25^{\circ} \mathrm{C}$ was comparable to those evaluated for $\mathrm{MmNi}_{4.2} \mathrm{Al}_{0.5} \mathrm{M}_{0.3}$ alloys $(\mathrm{M}=\mathrm{Cr}, \mathrm{Mn}, \mathrm{Fe}, \mathrm{Co}, \mathrm{Ni})$ at $30^{\circ} \mathrm{C}^{11}$ and $\mathrm{MmNi}_{3.55} \mathrm{Co}_{0.75} \mathrm{Mn}_{0.4} \mathrm{Al}_{0.3}$ alloy. ${ }^{12)}$ The $D^{*}$ value decreased with decreasing temperature from $6.0 \times 10^{-9} \mathrm{~cm}^{2} \mathrm{~s}^{-1}$ at $0^{\circ} \mathrm{C}$ to $1.7 \times 10^{-10} \mathrm{~cm}^{2} \mathrm{~s}^{-1}$ at $-40^{\circ} \mathrm{C}$, suggesting that the absorbed hydrogen is stabilized at relatively low temperatures. This is supported from the fact that the equilibrium hydrogen pressure of the $\mathrm{MmNi}_{3.6} \mathrm{Mn}_{0.4} \mathrm{Al}_{0.3} \mathrm{CO}_{0.7}$ alloy determined from PCT curve also decreases with decreasing temperature. ${ }^{2)}$ The activation energy for the hydrogen diffusion $\left(E_{\mathrm{a}, \mathrm{diff}}\right)$ determined from the slope of the straight line in Fig. 2 was $41.7 \mathrm{~kJ} \mathrm{~mol}^{-1}$.

3. 1. 2 Charge-transfer reaction on the electrode surface The exchange current density $\left(i_{0}\right)$ for the hydrogen electrode reaction is a measure of electrocatalytic activity for the charge-transfer reaction on the elec-

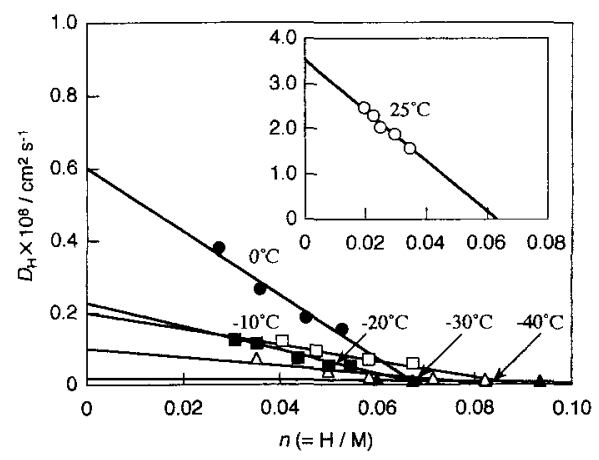

Fig. I Fick's diffusion coefficients of hydrogen $\left(D_{\mathrm{H}}\right)$ in the bulk of $\mathrm{MmNi}_{3.6} \mathrm{Mn}_{0.4} \mathrm{Al}_{0.3} \mathrm{Co} 0.7$ alloy electrode as a function of hydrogen concentration $(n)$ at various temperatures.

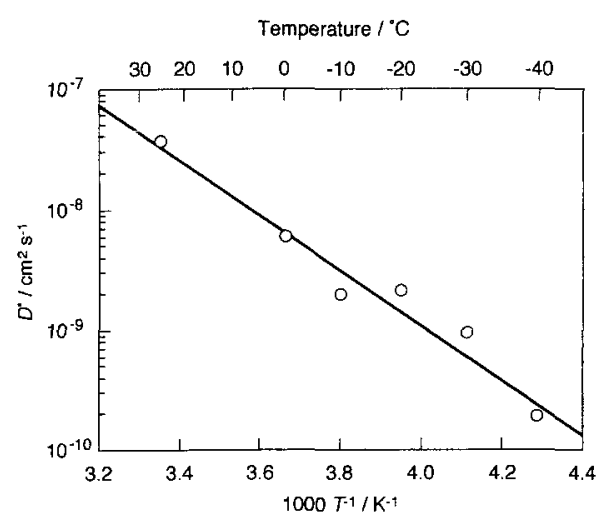

Fig. 2 Arrhenius plot of Einstein diffusion coefficient of hydrogen $\left(D^{*}\right)$ in the bulk of $\mathrm{MmNi}_{3.6} \mathrm{Mn}_{0.4} \mathrm{Al}_{0.3} \mathrm{Co}_{0.7}$ alloy electrode. 


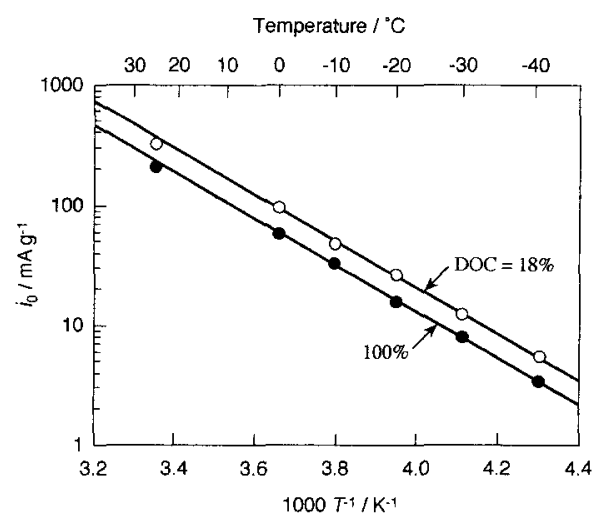

Fig. 3 Arrhenius plots of exchange current density $\left(i_{0}\right)$ for $\mathrm{MmNi}_{3.6} \mathrm{Mn}_{0.4} \mathrm{Al}_{0.3} \mathrm{Co}_{0.7}$ alloy electrode with different depths of charge (DOC).

trode surface. ${ }^{8}$ For the $\mathrm{MmNi}_{3.6} \mathrm{Mn}_{0.4} \mathrm{Al}_{0.3} \mathrm{Co}_{0.3}$ alloy electrode, the $i_{0}$ values were determined at two depths of charge (DOCs) and various temperatures. As a result, linear current-potential curves were observed in any case. The $i_{0}$ values were calculated from the slope of each straight line and summarized in Fig. 3. The DOC values of $18 \%$ and $100 \%$ correspond to solid-solution ( $\alpha$-phase) and hydride ( $\beta$-phase) for the $\mathrm{MmNi}_{3.6} \mathrm{Mn}_{0.4} \mathrm{Al}_{0.3} \mathrm{Co}_{0.7}$ alloy, respectively. ${ }^{14}$ As can be seen from Fig. 3, the logarith-

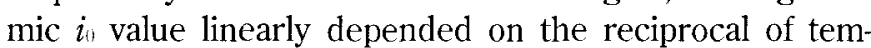
perature in both cases. Moreover, the $i_{0}$ value at the DOC value of $18 \%$ was larger than that at $100 \%$ irrespective of temperature. This may be ascribed to the difference in coverage of atomic hydrogen adsorbed on the electrode surface. The surface coverage of hydrogen at which the alloy was converted into the $\beta$-phase is about 0.8 and the adsorbed hydrogen blocks the electrode surface, inhibiting the charge-transfer reaction. ${ }^{14)}$ The activation energies for the charge-transfer reaction $\left(E_{\mathrm{a}, \mathrm{ct}}\right)$ determined from the slope of these straight lines were $37.2 \mathrm{~kJ}$ $\mathrm{mol}^{-1}$ in both cases.

\section{1. 3 Electric conductivity of KOH solution}

Figure 4 shows Arrhenius plots of the electric conductivity for $\mathrm{KOH}$ solutions with different concentrations. The Arrhenius plots of the electric conductivity were almost linear in any case, but they deviated negatively at relatively low temperatures sooner or later due to the freezing of the $\mathrm{KOH}$ solutions. $6 \mathrm{M} \mathrm{KOH}$ solution showed the

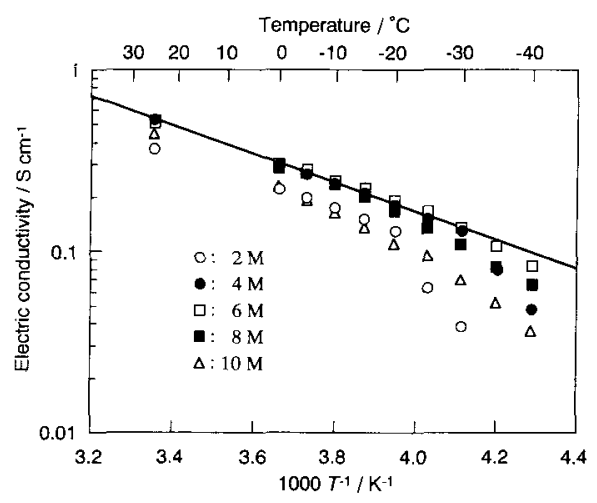

Fig. 4 Arrhenius plots of electric conductivity for $\mathrm{KOH}$ solution with different concentrations. highest electric conductivity at each temperature, suggesting that this solution is suitable for an electrolyte solution even at relatively low temperatures. The activation energy for the electric conductivity of $6 \mathrm{M} \mathrm{KOH}$ solution $\left(E_{\mathrm{a}, \mathrm{sol}}\right)$ determined from the slope of the Arrhenius plot in the temperature range of $25^{\circ} \mathrm{C}$ to $-30^{\circ} \mathrm{C}$ was $15.2 \mathrm{~kJ}$ $\mathrm{mol}^{-1}$. The $E_{\mathrm{a}, \mathrm{sol}}$ value was much smaller than the $E_{\text {a,diff }}$ and $E_{\mathrm{a}, \mathrm{ct}}$, values, clearly indicating that the electric conductivity is not a dominant factor in the discharge process at relatively low temperatures.

3. 1. 4 AC impedance spectroscopy In order to verify the dependence of temperature for each step, $\mathrm{AC}$ impedance spectroscopy was also measured in the same temperature range. The electrochemical impedance spectra for the alloy electrode at $\mathrm{DOC}=18 \%$ measured from $10 \mathrm{kHz}$ to $10 \mathrm{mHz}$ are shown as Nyquist plots in Fig. 5 . Each spectrum fitted a curve simulated by using the equivalent circuit proposed by Kuriyama et al.$^{15)}$ which consisted of a small and a large arcs with a gap assigned to a contact resistance between alloy powders $\left(R_{3}\right)$. The large arc in low frequency region assigned to a chargetransfer resistance on alloy surface $\left(R_{4}\right)$ was drastically enlarged as temperature decreased, indicating an increase in the charge-transfer resistance. This supports the decrease in the electrocatalytic activity at relatively low temperatures as shown in Fig. 3. The Warburg impedance assigned to the hydrogen diffusion in the alloy bulk was not observed in the impedance spectra below $0^{\circ} \mathrm{C}$, although it was observed at $25^{\circ} \mathrm{C}$. In addition, no Warburg impedance was observed for all DOCs in this frequency range at $-40^{\circ} \mathrm{C}$. This may be attributed to the slow hydrogen diffusion in the alloy bulk at relatively low temperatures $^{16)}$ as shown in Fig. 1 and/or large chargetransfer resistance.
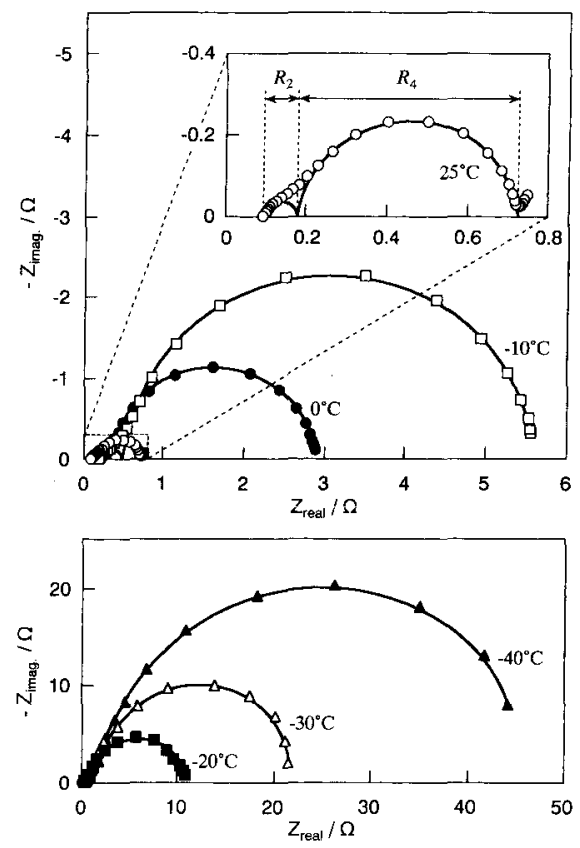

Fig. 5 Impedance spectra for $\mathrm{MmNi}_{3.6} \mathrm{Mn}_{0.4} \mathrm{Al}_{0.3} \mathrm{Co}_{0.7}$ alloy electrode at $\mathrm{DOC}=18 \%$ and various temperatures. Solid lines show simulation curves. $R_{2}$ and $R_{4}$ are defined in the text. 


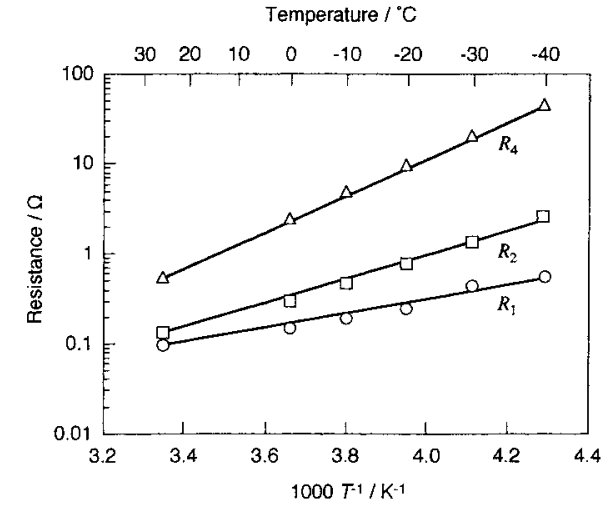

Fig. 6 Electrolyte solution resistance $\left(R_{1}\right)$, contact resistance between a current collector and alloy particles $\left(R_{2}\right)$ and charge-transfer resistance $\left(R_{4}\right)$ for $\mathrm{MmNi}_{3.6} \mathrm{Mn}_{0.4} \mathrm{Al}_{0.3} \mathrm{Co}_{0.7}$ alloy electrode.

The impedance data at various temperatures are summarized in Fig. 6. Since the $R_{3}$ value was rarely found in all cases, it was omitted in this figure. This figure shows that the electrolyte solution resistance $\left(R_{1}\right)$, the contact resistance between current collector and alloy particles $\left(R_{2}\right)$ and the $R_{4}$ value increased with decreasing temperature, suggesting the increase in the hydrogen overpotential at relatively low temperatures. ${ }^{17,18)}$ Moreover, the value of double-layer capacitance $\left(Q_{1}\right)$ scarcely changed with temperature, indicating that the effective surface area of the electrode was constant. ${ }^{14 \text { ? }}$

The activation energies for the charge-transfer reaction on the electrode surface and the electric conductivity of the $6 \mathrm{M} \mathrm{KOH}$ solution can be evaluated from the plots of $R_{4}$ and $R_{1}$, respectively. As a result, the $E_{\mathrm{a}, \mathrm{ct}}$ and $E_{\mathrm{a}, \mathrm{sul}}$ values were $39.0 \mathrm{~kJ} \mathrm{~mol}^{-1}$ and $16.5 \mathrm{~kJ} \mathrm{~mol}^{-1}$, respectively. These values are in fair agreement with those determined in Figs. 2 and 3, suggesting the validity of the evaluation methods.

\section{1. 5 Comparison of the activation energy}

Figure 7 shows the comparison of the $E_{\mathrm{a} \text {,diff, }} E_{\mathrm{a}, \mathrm{ct}}$ and $E_{\mathrm{a}, \mathrm{sol}}$ values. As can be seen from this figure, the activation energy for the charge-transfer reaction on the electrode surface was comparable to that for the hydrogen diffusion in the alloy bulk and both values were much larger than the $E_{\text {a,sol }}$ value, indicating that both the charge-

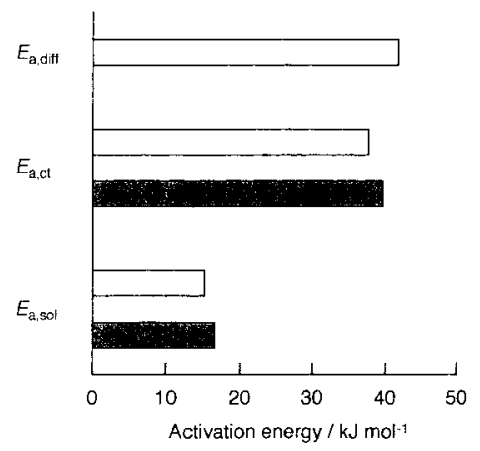

Fig. 7 Activation energies for hydrogen diffusion ( $\left.E_{\mathrm{a} \text {,diff }}\right)$, charge-transfer reaction $\left(E_{\mathrm{a}, \mathrm{ct}}\right)$ and electric conductivity of 6 $\mathrm{M} \mathrm{KOH}$ solution $\left(E_{\mathrm{a} \text {,sol }}\right)$. Dark lines show activation energies determined by $\mathrm{AC}$ impedance method. transfer reaction and hydrogen diffusion are ratedetermining even at relatively low temperatures as well as near room temperature. Therefore, the modification of the alloy bulk and/or surface must be essential for improving the dischargeability of the negative electrodes in $\mathrm{Ni}-\mathrm{MH}$ battery at relatively low temperatures.

\section{2 Improvement of dischargeability at relatively} low temperatures

\section{2. 1 Addition of $\mathrm{Mo}$ to the $\mathrm{MmNi}_{3.6} \mathrm{Mn}_{0.4} \mathrm{Al}_{0.3} \mathrm{Co}_{0.7}$}

alloy Figure 8 shows the $i_{0}$ value and maximum discharge capacity $\left(C_{\max }\right)$ for $\mathrm{MmNi}_{3.6} \mathrm{Mn}_{0.4} \mathrm{Al}_{0.3} \mathrm{Co}_{0.7} \mathrm{Mox}_{\mathrm{x}}$ alloy electrodes as a function of the $\mathrm{x}$ value at $25^{\circ} \mathrm{C}$. The $i_{0}$ value showed the maximum at $\mathrm{x}=0.3$, whereas the $C_{\max }$ value gradually decreased with increasing the addition of Mo due to the stabilization of its hydride. From the viewpoint of the $i_{0}$ and $C_{\max }$ values, $\mathrm{MmNi}_{3.6} \mathrm{Mn}_{0.4} \mathrm{Al}_{0.3} \mathrm{Co}_{0.7} \mathrm{Mo}_{0.3}$ alloy was the most appropriate composition.

The $i_{0}$ and $R_{4}$ values for the $\mathrm{MmNi}_{3.6} \mathrm{Mn}_{0.1} \mathrm{Al}_{0.3} \mathrm{Co}_{0.7} \mathrm{Mo}_{0.3}$ alloy electrode were determined from linear currentpotential curves and $\mathrm{AC}$ impedance spectra, respectively. These results showed that the $i_{0}$ value increased $c a .1 .3$ times by the addition of Mo irrespective of temperature, whereas the $R_{4}$ value decreased, strongly suggesting that the addition of Mo leads to the improvement of the electrocatalytic activity. In addition, the activation energy for the charge-transfer reaction on the surface of $\mathrm{MmNi}_{3, \mathrm{Mn}} \mathrm{Al}_{2 .} \mathrm{Co}_{0}-\mathrm{Mo}_{0.3}$ alloy electrode was $36.8 \mathrm{~kJ}$ $\mathrm{mol}^{-1}$, indicating that the electrocatalytic activity is slightly improved by the addition of Mo.

3. 2. 2 Morphology and crystallographic property of $\mathrm{MmNi}_{3.6} \mathrm{Mn}_{0.4} \mathrm{Al}_{0.3} \mathrm{Co}_{0.7} \mathrm{Mo}_{0.3}$ alloy In order to clarify the effect of added Mo on the electrocatalytic activity, the surface analysis for $\mathrm{MmNi}_{3.6} \mathrm{Mn}_{0.4} \mathrm{Al}_{0.3} \mathrm{Co}_{0.7} \mathrm{Mo}_{0.3}$ alloy electrode before and after charge-discharge test was carried out. Figure 9 shows the SEM images and EPMA maps of the surface components for $\mathrm{MmNi}_{3.6} \mathrm{Mn}_{0.4} \mathrm{Al}_{0.3} \mathrm{Co}_{0.7} \mathrm{Mo}_{0.3}$ alloy. Before cycle test (see Fig. 9 (a)), in the EPMA maps Mo-rich area was clearly observed and Co was also shown intensively in the same area in the place of $\mathrm{Ni}$, suggesting that Mo precipitated together with some $\mathrm{Co}$ as a second phase on the grain boundary, whereas $\mathrm{Ni}$ was diminished. By XRD analysis, the second phase was identified as $\mathrm{Mo}_{6} \mathrm{Co}_{7}$ or $\mathrm{MoCo}_{3}$. A quantitative EPMA analysis of this alloy revealed that the distributions of the various components expect Mo

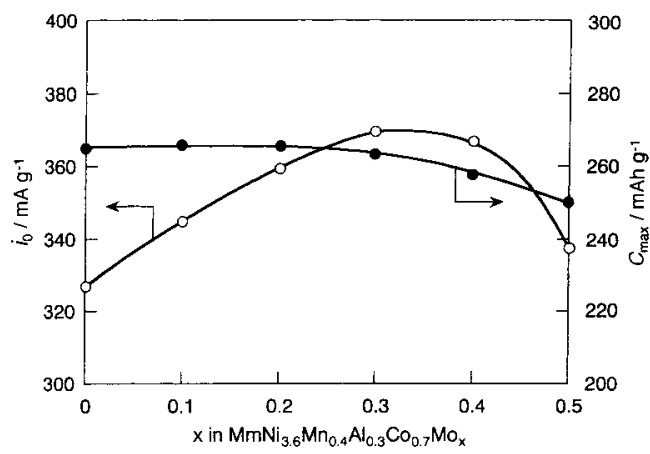

Fig. 8 Exchange current density $\left(i_{0}\right)$ and maximum discharge capacity $\left(C_{\text {max }}\right)$ for $\mathrm{MmNi}_{3,6} \mathrm{Mn}_{0.4} \mathrm{Al}_{0.3} \mathrm{Co}_{0.7} \mathrm{Mox}_{0}(0 \leq \times$ $\leq 0.5)$ alloy electrodes at $25^{\circ} \mathrm{C}$. 

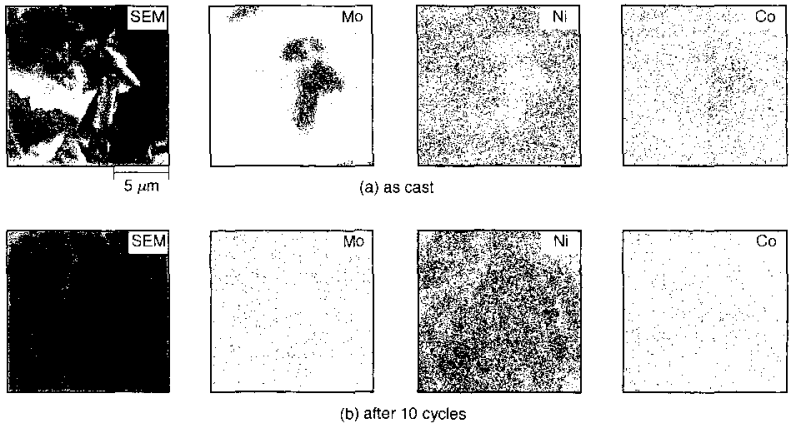

Fig. 9 SEM images and EPMA maps of surface components for $\mathrm{MmNi}_{3.6} \mathrm{Mn}_{0.4} \mathrm{Al}_{0.3} \mathrm{CO}_{0.7} \mathrm{Mo}_{0.3}$ alloy (a) as cast and (b) after 10 charge-discharge cycles.

within the main phase is similar with that of the Mo-free alloy. After 10 cycles (Fig. 9 (b)), the second phase disappeared and $\mathrm{Mo}$ as well as $\mathrm{Ni}$ and Co distributed almost homogeneously on the surface. The second phase exposed on the alloy surface by the initial activation is expected to dissolve into $6 \mathrm{M} \mathrm{KOH}$ solution, followed by reprecipitating on the electrode surface ${ }^{19)}$ during the charge-discharge cycling. $\mathrm{AC}$ impedance measurement for the $\mathrm{MmNi}_{3.6} \mathrm{Mn}_{0.4} \mathrm{Al}_{0.3} \mathrm{Co}_{0.7} \mathrm{Mo}_{0.3}$ alloy electrode after 10 cycles reveraled that an impedance spectrum assigned to the dissolution/deposition reaction was rarely found, suggesting that the reaction proceeds substantially during the initial activation. According to the Brewer-Engel theory, the appropriate combination of transition metals having vacant d-orbitals and internally paired d-electrons such as $\mathrm{MoCO}_{3}$ and $\mathrm{MoNi}_{3}$ can exert a synergistic effect on the electrocatalytic activity for the hydrogen electrode reaction. ${ }^{20)}$ The codeposited layer such as $\mathrm{Co} / \mathrm{Mo}$ alloy formed on the electrode surface may have worked as an electrocatalytic site. In the absence of the codeposited layer, the charge-transfer reaction could occur on the surface with oxidized film such as $\mathrm{La}_{2} \mathrm{O}_{3}$, leading to a relatively high overpotential. ${ }^{21}$ Reaction rates would be most rapid if the high electrocatalytic layer exists on the alloy surface. This leads to the slight decrease of the activation energy for the charge-transfer reaction, although the addition of Mo was not so much influenced due to the limited amounts of Mo.

\section{2. 3 Improvement of high-rate dischargeability} Figure 10 shows the $\mathrm{HRD}$ values for $\mathrm{MmNi}_{3.6} \mathrm{Mn}_{0.4} \mathrm{Al}_{0.3} \mathrm{Co}_{0.7}$ and $\mathrm{MmNi}_{3.6} \mathrm{Mn}_{0.4} \mathrm{Al}_{0.3} \mathrm{Co}_{0.7} \mathrm{Mo}_{0.3}$ alloy electrodes at various discharge current densities and temperatures. As can be seen from this figure, linear dependencies between the HRD value and discharge current density were observed in all cases. The HRD values for both alloy electrodes showed about $90 \%$ even at $1000 \mathrm{~mA} \mathrm{~g}^{-1}$ at $25^{\circ} \mathrm{C}$. The decrement of the $\mathrm{HRD}$ value for $\mathrm{MmNi}_{3.6} \mathrm{Mn}_{0.4} \mathrm{Al}_{0.3} \mathrm{Co}_{0.7}$ alloy electrode increased drastically with decreasing temperature. Especially at $-40^{\circ} \mathrm{C}$, the $\mathrm{HRD}$ value was nearly zero even at $100 \mathrm{~mA} \mathrm{~g}^{-1}$, leading to the decrease of the discharge capacity at relatively low temperatures. However, the decrement of the HRD value for $\mathrm{MmNi}_{3.6} \mathrm{Mn}_{0.4}$ $\mathrm{Al}_{0.3} \mathrm{CO}_{0.7} \mathrm{Mo}_{0.3}$ alloy electrode was much smaller than that for $\mathrm{MmNi}_{3.6} \mathrm{Mn}_{0.4} \mathrm{Al}_{0.3} \mathrm{CO}_{0.7}$ alloy electrode. Thus the addition of Mo to the alloy led to the improvement of the

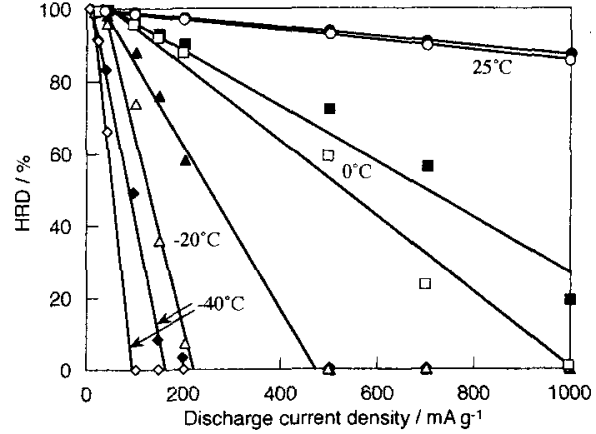

Fig. 10 High-rate dischargeability (HRD) as a function of discharge current density for $\mathrm{MmNi}_{3.6} \mathrm{Mn}_{0.4} \mathrm{Al}_{0.3} \mathrm{CO}_{0.7}$ (open symbols) and $\mathrm{MmNi}_{3.6} \mathrm{Mn}_{0.4} \mathrm{Al}_{0.33} \mathrm{Co}_{0.7} \mathrm{Mo}_{0.3}$ (closed symbols) alloy electrodes at various temperatures.

electrocatalytic activity on the electrode surface or the dischargeability at relatively low temperatures.

\section{Conclusions}

The activation energies for the hydrogen diffusion in the alloy bulk, the charge-transfer reaction on the electrode surface and the electric conductivity of $6 \mathrm{M} \mathrm{KOH}$ solution ( $E_{\mathrm{a}, \mathrm{diff}}, E_{\mathrm{a}, \mathrm{ct}}$ and $\left.E_{\mathrm{a}, \mathrm{sol}}\right)$ were evaluated by several electrochemical methods. The $E_{\mathrm{a} \text {,diff, }} E_{\mathrm{a}, \mathrm{ct}}$ and $E_{\mathrm{a} \text {,sol values }}$ were $41.7,37.2$ and $15.2 \mathrm{~kJ} \mathrm{~mol}^{-1}$, respectively. Since the $E_{a, \text { diff }}$ and $E_{\text {a,ct }}$ values were close each other and they were much larger than the $E_{\text {a.sol }}$ value, it was concluded that both the hydrogen diffusion and the charge-transfer reaction significantly influenced the discharge process at relatively low temperatures. The addition of Mo to the $\mathrm{MmNi}_{3.6} \mathrm{Mn}_{0.4} \mathrm{Al}_{0.3} \mathrm{Co}_{0.7}$ alloy was effective for the improvement of the dischargeability at relatively low temperatures.

\section{Acknowledgement}

This study was partially supported by Grants-in-Aid for Scientific Research on Priority Areas (B) of "Ionics Devices" (No.11229205), Scientific Research on Priority Areas (A) of "New Protium Function" (No. 10148105) from the Ministry of Education, Science, Sports and Culture of Japan and Scientific Research (C) No. 11650861 from Japan Society for the Promotion Science.

\section{References}

1) C. Iwakura and M. Matsuoka, Prog. Batteries \& Battery Mater., 10, 81 (1991).

2) T. Sakai, M. Matsuoka, and C. Iwakura, Handhook on the Physics and Chemistry of Rare Earths (Eds. K. A. Gschneidner, Jr. and L. Eyring), Vol. 21, Elsevier, Amsterdam, p. 133 (1995).

3) T. Sakai, H. Miyamura, N. Kuriyama, I. Uehara, M. Muta, A. Takagi, U. Kajiyama, K. Kinoshita, and F. Isogai, $J$. Alloys Comp., 192, 158 (1993).

4) T. Sakai, H. Miyamura, N. Kuriyama, A. Kato, K. Oguro, H. Ishikawa, and C. Iwakura, J. Less-Common Met., 159, 127 (1990).

5) H. Senoh, Y. Hara, H. Inoue, and C. Iwakura, Electrochim. Acta, 46, 967 (2001).

6) T. Sakai, H. Miyamura, N. Kuriyama, A. Kato, K. Oguro, 
and H. Ishikawa, J. Electrochem. Soc., 137, 795 (1990).

7) T. L. Markin, R. Bennett, N. J. Bridger, and R. M. Dell, Power Sources (Ed. J. Thompson), Vol. 8, Academic, London, p. 445 (1981).

8) P. H. L. Notten and P. Hokkeling, J. Electrochem. Soc., 138, 1877 (1991).

9) C. Iwakura, K. Fukuda, H. Senoh, H. Inoue, M. Matsuoka, and Y. Yamamoto, Electrochim. Acta, 43, 2041 (1998).

10) B. A. Boukamp, Solid State Ionics, 20, 31 (1986).

11) C. Iwakura, T. Oura, H. Inoue, M. Matsuoka, and Y. Yamamoto, J. Electoanal. Chem., 298, 37 (1995).

12) H. -S. Kim, M. Nishizawa, and I. Uchida, Electrochim. Acta, 45, 483 (1999).

13) W. -K. Choi, T. Tanaka, R. Miyauchi, T. Morikawa, H. Inoue, and C. Iwakura, J. Alloys Comp., 299, 141 (2000).
14) H. Senoh, K. Morimoto, H. Inoue, C. Iwakura, and P. H. L. Notten, J. Electrochem. Soc., 147, 2451 (2000).

15) N. Kuriyama, T. Sakai, H. Miyamura, I. Uehara, and H. Ishikawa, J. Alloys Comp., 202, 183 (1993).

16) W. -K. Choi, K. Yamataka, H. Inoue, and C. Iwakura, J. Alloys Comp., 290, 110 (1999).

17) G. Zheng, B. N. Popov, and R. E. White, J. Appl. Electrochem., 27, 1328 (1997).

18) L. Zhang, Electrochim. Acta, 43, 3333 (1998).

19) M. Pourbaix, Atlas Electrochemical Equilibria in Aqueous Solutions, Pergamon, Oxford (1966).

20) S. Trasatti, Advances in Electrochemical Science and Engineering (Eds. H. Gerischer and C. W. Tobias), Vol. 2, VCH, Weinheim, p. 1 (1992)

21) M. E. Fiorino, R. L. Opila, K. Konstadinidas, and W. C. Fang, J. Electrochem. Soc., 143, 2422 (1996). 